\title{
CORRESPONDENCE
}

\section{Sheila Jennett and Ludwig Guttmann}

Spinal Cord Series and Cases (2017) 3, 17031; doi:10.1038/ scsandc.2017.31; published online 20 July 2017

On 29-30 April 1999, my wife and I attended an unforgettable 2-day symposium on 'medicine and literature', held at The Royal College of Physicians and Surgeons of Glasgow, on the 400 centenary celebration. The Royal College Glasgow was founded by Peter Lowe after receiving a royal charter by James VI in 1599 as the Glasgow Faculty.

There I met two famous Glaswegians: Professor Sir Bryan Jennett (1926-2008) and his wife, Professor of physiology, Sheila Pope-Jennett (an Honorary member of staff in the Division of Neuroscience and Biomedical Systems). Sir Bryan asked me to send his best regards to a friend in Israel, who dedicated his professional life to the treatment of patients with severe brain injuries. I trust that Jennett and Teasdale's 'Glasgow coma scale' is well-known around the globe.

Later, during dinner, Sheila Jennett told me that once upon a time, she worked with Dr Ludwig Guttmann at Stoke Mandeville.

I do not recall if she told me when and for how long she worked at Stoke Mandeville. I believe that this fact is unknown to those who are interested in the history of spinal cord injuries.

Recently, I corresponded with her and with one of her sons, Peter (a project manager), who kindly sent me a few photographs.

In one picture, taken in September 1952, she sits with two distinguished assistants to Guttmann at Stoke Mandeville, the surgeons Dr Jack Walsh (1917-1992) and Dr Lorenz Michaelis (1902-1979) who are standing.

Peter Jennett wrote that: 'Sitting- four months pregnant (with me..)' and 'she finished (medical studies), fully qualified as a hospital doctor. Then later in her 40's, after we had moved to Glasgow in 1963 and she had given birth to her fourth child in 1964, embarked on a doctorate related to respiratory physiology'.

In another picture (during the Stoke Mandeville Games of 1952), we can clearly see Sir Ludwig and Ms Joan Scruton writing notes. The first two countries who took part in that Games were Great Britain and the Netherlands. In 1953, more countries were

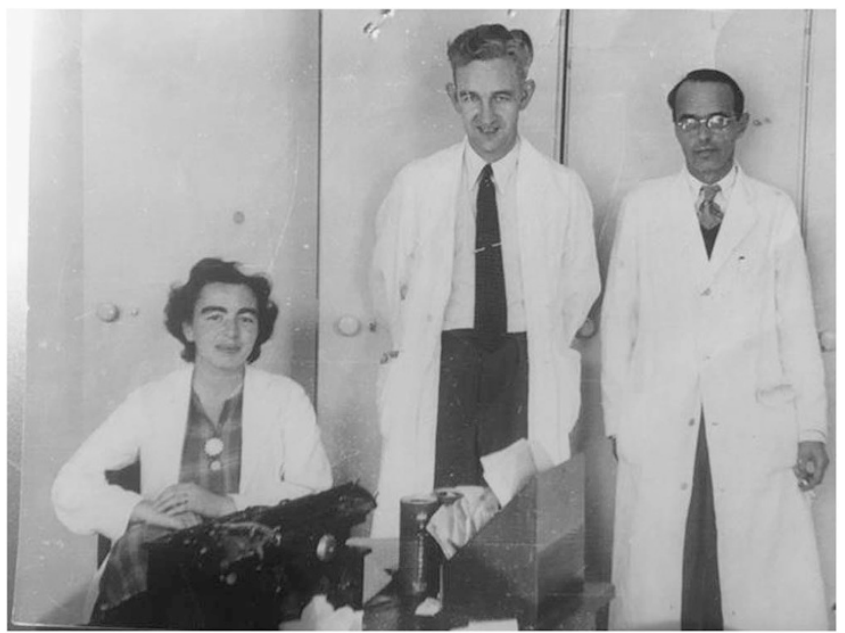

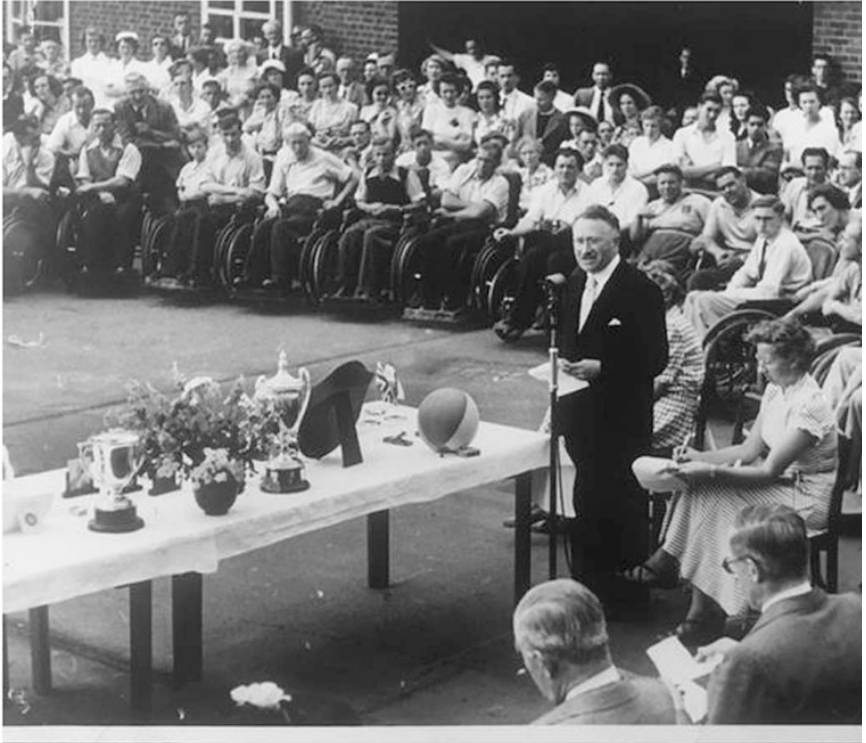

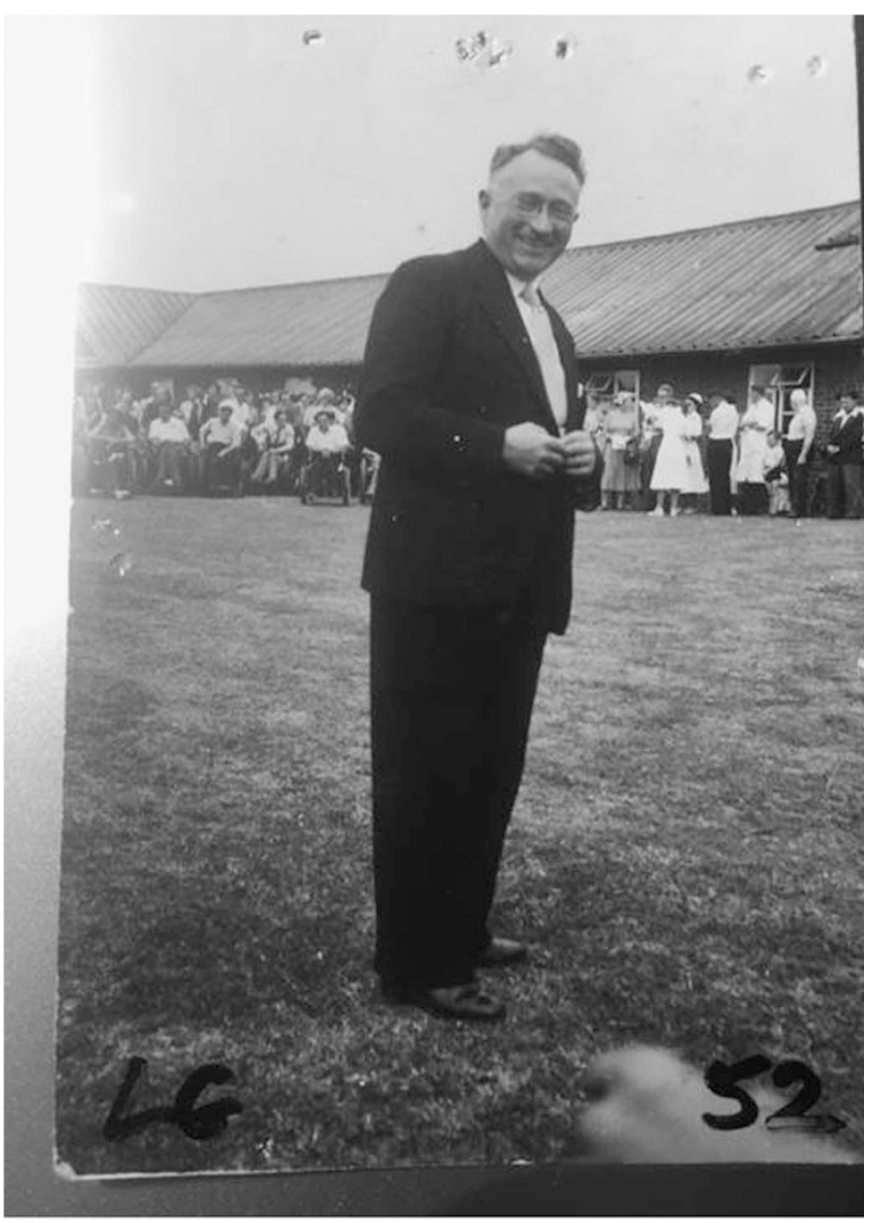


represented including Israel led by Dr Ralph Spira who had also been trained by Guttmann at Stoke Mandeville. ${ }^{1}$

Professor Sheila Jennett had published articles on spinal cord-injured patients s,3 $^{2,3}$ and I did not find any article published with her husband. She published in 2003 (with Colin Blackmore) 'The Oxford Companion to the Body', and the Churchill Livingstone's Dictionary of Sport and Exercise Science and Medicine (2009).

I believe that these pictures are shown for the first time. My sincere thanks to Mr Peter Jennett.

\section{COMPETING INTERESTS}

The author declares no conflict of interest.
Avi Ohry

Rehabilitation Medicine, Reuth Medical Center, Tel Aviv, Israel Correspondence: A Ohry (aohry@post.tau.ac.il)

\section{REFERENCES}

1 Scruton J. Stoke Mandeville Road to the Paralympics. The Peterhouse Press: Aylesbury, UK, 1998, pp 70-72.

2 Jennett $\mathrm{S}$. The response of heart rate to hypoxia in man after cervical spinal cord transection. Paraplegia 1970; 8: 1-13.

3 Jennett $\mathrm{S}$. The effect of brief moderate hypoxia and abrupt reoxygenation on the heart rate in human subjects with cervical spinal transection. J Physiol 1969; 205: 35P-36P. 